REIS, Elisa Pereira. Processos e escolhas: estudos de sociologia política. Rio de Janeiro : ContraCapa, 1998.

\title{
HISTÓRIA E SOCIOLOGIA: UM PAR NECESSÁRIO
}

\author{
Renato Monseff Perissinotto \\ Universidade Federal do Paraná
}

Quais as vantagens que os historiadores e os sociólogos poderiam retirar de uma íntima relação entre as suas disciplinas? De que forma História e Sociologia podem se articular para, ao mesmo tempo, produzir um tipo de conhecimento que não se limite a retratar o contingente e que não produza generalizações abstratas? Que tipo de conhecimento resultaria de uma articulação entre essas duas disciplinas? São essas questões que Elisa Pereira Reis, professora do Instituto de Filosofia e Ciências Sociais da UFRJ, procura responder em seu trabalho.

O livro, como informa a autora, é composto por vários artigos escritos em momentos diferentes de sua carreira de pesquisadora e professora e que trafegam na fronteira da Sociologia e da Ciência Política. Apesar da grande diversidade de temas tratados e dos momentos distintos em que os textos foram escritos, o livro tem uma relativa unidade. Há em parte significativa dos seus capítulos uma preocupação em responder as questões citadas no parágrafo acima. A unidade do livro reside, mais especificamente, em dois pontos.

Primeiro, Reis se propõe a pensar os processos históricos como frutos da conjugação entre determinações estruturais e escolhas contingentes. Assim, para a autora, "constrangimentos estruturais, por um lado, e opções históricas, por outro, são os dois termos gerais que permitem conceber uma articulação entre pressupostos epistemológicos fatalistas e voluntaristas, assim como entre premissas coletivistas e individualistas" (p. 7). Trata-se, ao meu ver, de uma postura teórico-metodológica produtiva na medida em que evita o exagero de se enfatizar uma dimensão dos fenômenos sociais em detrimento de outra, exagero tão recorrente nas Ciências Sociais. A autora recusa, dessa forma, a oposição estéril entre estrutura e ação, entre constrangimentos objetivos e escolhas contingentes, optando, ao contrário, por um tipo de abordagem que se preocupa em pensar a articulação entre ambos como o caminho mais fértil para se explicar acontecimentos históricos ${ }^{1}$.

Mas como realizar teoricamente essa articulação? Aqui encontramos o segundo ponto sobre o qual reside a unidade do livro em questão. A autora propõe que o melhor caminho para se compreender os fenômenos sócio-históricos está em promover uma articulação permanente entre teoria sociológica e história, entre generalização e singularidade. Essa conjugação entre sociologia e história é positiva exatamente em função de sua "tolerância analítica que faz do diálogo entre parâmetros estruturais e escolhas individuais a senha da relevância da explicação" (p. 8). Contudo, o fato de tal articulação ser benéfica para o conhecimento nas ciências sociais, não quer dizer que ela tenha sido, até agora, resolvida de forma satisfatória na teoria sociológica clássica ou contemporânea. Por exemplo, segundo a autora, na obra de Weber, representante clássico dessa perspectiva que visa conjugar trabalho de elaboração conceitual e história comparada, "é mais fácil entender determinações estruturais e escolhas individuais como explicações paralelas que integradas. Da mesma forma, os exercícios teóricos sintéticos contemporâneos são mais convincentes como pluralismo

\footnotetext{
1 Nesse sentido, Reis encontra-se ao lado de nomes importantes da teoria social. Anthony Guidens, por exemplo, nos seus comentários ao debate iniciado por Jon Elster no início dos anos oitenta, discute a ênfase dada por este autor à teoria da ação, colocando-a em frontal oposição à abordagem estrutural. Para G uidens, esse dualismo metodológico tem obstruído a teoria social há muito tempo. Cf. G UIDENS, 1982, p. 534. Segundo Steven Lukes, a pesquisa sociológica deve procurar a interação entre essas duas perspectivas, ou seja, deve perceber que os indivíduos agem juntos e uns sobre os outros - e que essa ação tem consequências importantes - mas agem também dentro de grupos, organizações e através de comportamentos socialmente estruturados que, por isso, não podem ser reduzidos às motivações individuais. Cf. LUKES, 1980, p. 45-47
} 
analítico que como sínteses lógicas” (p. 8).

Como se vê, o objetivo da autora é ambicioso. De um lado, constata-se a vantagem explicativa do método que articula determinações estruturais e ações contingentes, o que, por sua vez, deve ser feito através de uma articulação entre sociologia e história; por outro lado, constata-se que nem a sociologia clássica nem a contemporânea realizaram tal tarefa a contento. O objetivo geral do livro parece-me ser, portanto - em meio aos vários objetivos particulares dos diversos capítulos - , dar uma contribuição a essa questão teóricometodológica ${ }^{2}$. Isso, por si só, já faz do livro de Reis um acontecimento a ser comemorado. Como já foi dito uma vez, sobretudo na Ciência Política brasileira tem predominado uma tendência a se "contar" a história, perdendo-se de vista a "explicação" como o objetivo máximo do cientista social. Assim, a ênfase na busca de generalizações historicamente embasadas é algo certamente louvável. Nesse sentido, um dos objetivos dessa resenha, além de apresentar ao leitor uma breve descrição do conteúdo de cada um dos capítulos que compõem o livro, é ver em que medida a autora cumpre esse que nos parece ser o seu objetivo maior. Ou seja, trata-se de saber se Reis consegue, nas suas análises subseqüentes, elaborar de fato uma articulação entre sociologia e história, entre estrutura e contingência, superando o tratamento dessas duas dimensões como linhas paralelas de argumentação, ou se tal articulação permanece, nos seus textos, apenas uma palavra de ordem teórica.

A primeira parte do livro, essencialmente dedicada a questões de teoria social, é formada por três capítulos: "Generalização e singularidade nas Ciências Humanas", "Sobre a cidadania" e "Reflexões sobre o homo sociologicus".

O primeiro desses capítulos, dedicado basicamente a discutir as questões centrais apresentadas acima, parece-me o mais interessante de todos eles. Num primeiro momento, Reis procura mostrar como o par Teoria/ História foi articulado pelos clássicos da Sociologia (Marx, Weber e Durkheim). A autora mostra uma clara preferência pela abordagem weberiana. De um lado, por que a perspectiva marxista parece menosprezar o caráter dinâmico da elaboração teórica, dinamicidade esta que seria dada pela própria pesquisa empírica. Assim, segundo Reis, a perspectiva marxista não "fala em fazer a teoria: a teoria está feita, ela já foi descoberta; a teoria é a verdade que a pesquisa empírica revela ou ilustra” (p. 14). De outro lado, Durkheim desprezaria a "causalidade histórica" em favor de uma concepção dos fenômenos sociais como fenômenos naturais, cujas causas particulares não interessa buscar (p. 16). Weber, por sua vez, defenderia a íntima relação entre Sociologia e História. Disciplinas próximas, porém não idênticas, pois, "enquanto a causalidade sociológica busca leis gerais, a causalidade histórica privilegia a seqüência singular de eventos que caracterizam um fenômeno histórico particular". Assim, para Weber, "grande parte do trabalho de conceituação e de tipificação [ou seja, de generalização] nas ciências sociais pressupõe a contribuição da história" (p. 15). Nos desenvolvimentos subseqüentes dessa posição autores como Barrington Moore e Reinhard Bendix levaram adiante a idéia de que a causalidade histórica ao mesmo tempo autoriza as generalizações da Sociologia e as qualifica, mostrando os seus limites. Dessa articulação surge então o paradigma da Sociologia Histórica: a busca da causalidade da longa duração, a ênfase no estudo dos fenômenos políticos (formação de impérios, construção de Estados nacionais etc.) e o uso do método comparativo como instrumento que permite a elaboração de generalizações historicamente embasadas. Tal paradigma permite, segundo a autora, a conjugação bastante proveitosa do singular e do genérico. Ambos seriam, na verdade, inseparáveis, como corpo e alma (p. 25), já

\footnotetext{
2 É preciso notar que a conjugação entre Sociologia e História não gera necessariamente um modelo de explicação que articule estrutura e ação (mesmo de maneira insatisfatória). Barrington Moore e Theda Skocpol, por exemplo, dois autores citados por Reis como praticantes dessa variante teórica, são conhecidos representantes da corrente "estrutural" da Sociologia Histórica, criticados por não levarem em conta nas suas análises a ação humana. O u seja, eles procuram explicar macro-processos históricos sem mostrar como tais processos se traduzem em ações e escolhas contingentes. Cf., por exemplo, KISER, 1996, p. 249-271. Nesse sentido, temos, na verdade, dois problemas que podem ou não estar conjugados. De um lado, a questão da articulação entre análise histórica e teoria sociológica, ligada ao problema da relação entre singularidade e generalização; de outro, o problema da articulação entre determinações estruturais e escolhas contingentes para a explicação dos processos históricos. Esses dois pares (Sociologia/ História e estrutura/ ação) podem estar relacionados, mas não estão necessariamente. Contudo, se, de um lado, atribuímos à Sociologia o papel de produzir generalizações e aceitamos que estas só podem ser elaboradas através da identificação daquilo que é invariante, isto é, estrutural, e, de outro, atribuímos à História a função de nos revelar o elemento conjuntural dos fatos singulares, isto é, as ações e escolhas contingentes feitas pelos atores sociais, então teremos uma articulação entre aqueles dois pares. Pelo que pude entender das posições de Reis, parece ser essa a sua intenção neste livro.
} 
que o genérico só pode ser formulado a partir dos dados singulares e estes, por sua vez, não têm valor heurístico se não gerarem uma explicação generalizante ${ }^{3}$.

O capítulo "Sobre a Cidadania" é uma espécie de ilustração de como a história permite elaborações conceituais. O conceito de cidadania, da sua gênese até os seus significados mais recentes, expressa como mudanças históricas foram apreendidas pela teoria sociológica. Seria, portanto, um caso exemplar de como os conceitos têm origem em singularidades históricas, mas, ao mesmo tempo, ajudam a transcendê-las em busca de generalizações que permitem uma melhor compreensão dos processos históricos singulares. Dito isso, o presente capítulo se limita a apontar as ambigüidades do conceito de cidadania e a relatar a sua trajetória, cujo traço essencial seria um processo contínuo de inclusão de novos atores sociais no âmbito dos direitos.

A relação entre indivíduo e sociedade, entre estrutura social e human agency parece ser a questão central do terceiro capítulo desta primeira parte, "Reflexões sobre o homo sociologicus". Mais uma vez, essa questão aparece através das considerações da autora sobre dois clássicos da teoria sociológica: Durkheim e Weber ${ }^{4}$. Segundo Reis, para Durkheim a sociedade tem precedência lógica sobre o indivíduo, sendo este identificado com uma dimensão intrinsecamente coletiva. Dessa forma, este autor recusa veementemente premissas individualistas de análise (p. 50). O indivíduo seria apenas uma criação social e o social, para ser compreendido, não pode jamais ser reduzido a fundamentos psicológicos sociais ou individuais (p. $51 \mathrm{e} 52$ ). Embora reconheça o valor das contribuições durkheimianas, a autora, mais uma vez, apresenta uma clara preferência pelas posições weberianas na medida em que, para ela, este autor recupera para a Sociologia os fundamentos volitivos da ação social ${ }^{5}$. A sociedade e suas estruturas não são, para Weber, uma realidade em si, mas sim realidades produzidas pelos próprios homens, que lhes conferem sentido (p. 57-58). Mas Weber não cairia num reducionismo individualista na medida em que as motivações individuais levam os homens a escolher alternativas de ação circunscritas por condições histórico-estruturais particulares.

Portanto, os três textos que compõem a primeira parte do trabalho de Elisa Pereira Reis procuram, de uma forma ou de outra, trabalhar num nível teórico com as questões centrais do seu trabalho, isto é, com a relação entre História e generalização conceitual, entre estrutura e ação. Embora a recorrência a Durkheim e Weber (e a Marx menos) seja sempre fundamental numa discussão dessa natureza, é um pouco decepcionante para o leitor interessado no assunto e que tenha alguma intimidade com a teoria sociológica a ênfase dada por Reis aos trabalhos clássicos. De um lado porque, como ela mesmo diz, tais questão não foram plenamente resolvidas naqueles estudos; de outro, porque há um interesse intrínseco para o leitor nas discussões mais atuais.

A Segunda parte do livro de Reis é também composta por três capítulos, todos eles dedicados à análise de uma situação histórica específica a partir da qual a autora procura elaborar, ainda que provisoriamente,

\footnotetext{
3 Como bem mostra a autora, as "vantagens" da Sociologia Histórica não foram suficientes para convencer algumas outras vertentes teóricas da validade da conjugação entre teoria e história. Como representantes daqueles que rejeitam a abordagem histórica, ela cita explicitamente a teoria da escolha racional, que tende a generalizar o homo economicus para toda a vida social; o pós-modernismo, que rejeita a grande narrativa histórica, chamando a atenção para os processos de fragmentação, e os defensores do fim da história à la Fukuyama (p. 22-25). A autora, porém, dispensa tais críticas muito rapidamente. Vale lembrar que há tentativas recentes por parte de alguns estudiosos de juntar a teoria da escolha racional com a Sociologia Histórica, como é o caso de Edgar Kise, em texto citado na nota anterior. Além disso, embora não tenha nenhuma simpatia pessoal pelo pós-modernismo, parece-me um pouco exagerado identificar tal corrente como um misticismo teórico de fim de milênio (p. 24).

4 Pergunto-me porque Reis pouco se refere a Marx na análise desse problema. É amplamente conhecido que tal questão tem presença marcante nos trabalhos de Marx e dos marxistas. As referências de Marx ao capital como relação social e aos agentes como portadores dessa relação; a sua famosa frase acerca das condições em que os homens fazem a sua própria história; as considerações de Althusser e Sartre sobre a relação entre sujeitos históricos e estruturas sociais já seriam suficientes para a autora explorar a posição do marxismo acerca desse tema central do seu trabalho.

5 Embora isso não implique, por parte de Weber, uma recusa pura e simples de uma Sociologia organicista ou funcional. Para Weber, uma Sociologia deste tipo pode ser útil para a Sociologia Compreensiva na medida em que "1) pode servir para fins de orientação provisória e de ilustracão prática [..] 2) em determinadas circunstâncias ela pode nos ajudar a descobri aquela ação social cuja compreensão interpretativa seja importante para a explicação de uma conexão dada". Contudo, somente a análise feita pela Sociologia Compreensiva "nos proporciona aquilo que a compreensão sociológica da ação dos indivíduos tipicamente diferenciados [...] pode e deve nos oferecer", ou seja, a motivacãa do comportamento. Cf. WEBER, 1984, p. 13 e 15
} 
alguma generalização de caráter sociológico (p. 09).

O primeiro capítulo desta parte, "O Estado nacional como ideologia: o caso brasileiro", tem como objetivo o estudo do papel da ideologia na constituição de Estados nacionais, sendo o Estado brasileiro um caso bastante ilustrativo a esse respeito. Para a autora, os Estados nacionais são processos históricos particulares, porém com características compartilhadas que justificam um conceito genérico de Estado nacional (p. 67). Tal processo não envolve apenas a construção das instituições estatais como monopolizadoras da violência física, mas também de um certo sentimento de nacionalidade (legitimidade), que possui um ritmo histórico próprio. Esta dupla dimensão dos Estados nacionais, isto é, essa junção entre Estado e nacionalidade aponta, segundo a autora, para o caráter ideológico do processo de construção da nação (p. 68-69). Assim, o aspecto genérico da construção do Estado nacional no Brasil reside no papel de destaque que a ideologia teve nele; o seu elemento particular consiste numa idéia de nação que guiou a construção do Estado nacional e que sistematicamente enfatizou a idéia de nação como indivíduo coletivo (e não como uma coleção de indivíduos) que, por sua vez, se traduziu num padrão de interação entre Estado e sociedade em que esta ocupou, sistematicamente, uma posição subordinada frente à autoridade (p. 71). Esse processo ideológico subjacente à construção da nacionalidade brasileira remonta, é claro, a interesses e práticas concretas que a autora procura identificar no decorrer do texto, indo do Império à República populista. A conclusão é que, no Brasil, o processo de construção do Estado se adiantou em relação à constituição da nacionalidade. Esta, em rigor, só teve início no período Vargas, quando se estabelece uma orientação de inclusão política de setores até então marginalizados. Inclusão autoritária, certamente, mas inclusão. Dessa forma, a precocidade do Estado em relação à nação no processo histórico brasileiro coloca tarefas políticas muito claras, dentre as quais a principal parece ser o aprofundamento da responsabilidade social do Estado (p. 88).

O capítulo seguinte - "As transições do Leste e do Sul: o desafio teórico" —, é uma tentativa de teorizar sobre processos de transformações políticas e sociais a partir das experiências históricas da América Latina e do Leste Europeu. Mais especificamente, a comparação entre os acontecimentos históricos recentes nessas duas regiões pode fornecer, segundo a autora, "uma perspectiva útil para o desenvolvimento de uma macroteoria sociológica da mudança"(p. 92). Este capítulo seria, assim, uma demonstração prática de como a comparação histórica pode servir de base para a teorização sociológica, isto é, como ela pode nos ajudar a formular generalizações historicamente autorizadas (as convergências), sem, contudo, menosprezar as especificidades (as divergências) de cada processo particular.

O terceiro capítulo - "Desigualdade e solidariedade: uma releitura do 'familismo amoral' de Banfield" tem como objetivo elaborar uma reflexão sobre os problemas da solidariedade e da integração social em contextos de acentuada desigualdade (p.112). Utilizando o conceito de "familismo amoral" elaborado por Edward Banfield no seu livro The Moral Basis of a Backward Society ${ }^{6}$, Reis procura explicar as razões do baixo grau de participação e do parco interesse da população frente às questões públicas. Para a autora, a conjugação de falta de recursos e falta de incentivo à participação em atividades coletivas faz predominar no Brasil um amoralismo que afasta os indivíduos de atividades que levem em conta algo mais do que os interesses primários dos grupos mais imediatos a que pertencem (p. 116-17). Os traços de solidariedade social existentes na história do Brasil, e de outros países da América Latina, foram forjados pelo Estado nacional, sobretudo através da ideologia do desenvolvimentismo que, pela via do crescimento econômico e do ideal nacionalista, tornou viável um certo tipo de solidariedade nacional (p. 118-120). Porém, se mesmo naquele momento o espaço da solidariedade já era bastante restrito, com o fim do desenvolvimentismo e dos seus mecanismos de representação (o corporativismo em especial) ele se estreita ainda mais. A partir daí dois cenários são possíveis: o de uma crescente deterioração social que leve à ruptura e, depois, à refundação da sociedade civil ou a integração paulatina de grupos anteriormente excluídos (132).

Na terceira parte de seu livro, Reis dedica-se ao tema das relações entre a autoridade pública e os interesses privados, lançando mão, para tanto, de análises instigantes da história brasileira, sempre na busca da conjugação entre história e teoria sociológica. O primeiro capítulo desta parte - "As elites agrárias e a abolição da escravidão no Brasil" - é uma tentativa de analisar as inter-relações entre os determinantes estruturais dos interesses econômicos, a representação desses interesses no campo político e o processo de

\footnotetext{
$\overline{6}$ Segundo a autora, esse conceito foi formulado para explicar situações em que a solidariedade social e o sentimento de pertencimento a um coletivo não ultrapassam as fronteiras da vida familiar (p. 112).
} 
produção de decisões públicas referentes à questão da abolição da escravidão (p. 137).

O segundo capítulo - "Poder privado e construção do Estado sob a Primeira República" - condensa algumas idéias presentes na tese de doutoramento da autora (REIS, 1979), trabalho que, por sua vez, antecipava certas tendências mais recentes nos estudos sobre aqueles anos, qual seja, a revalorização do Estado como uma variável importante já naquele período. A perspectiva adotada aqui parece-me bastante interessante na medida em que foge a uma dicotomia tradicionalmente aceita, mas pouco frutífera, que vê a relação entre o "poder público" e o "poder privado" como entidades antagônicas e que, por isso, estabelecem entre si uma relação de soma-zero (p. 183) 7 . Reis mostra muito bem que o predomínio político das elites agrárias se, por um lado, permitiu a esses grupos uma posição de absoluto privilégio no que se refere à capacidade de influenciar as decisões públicas; por outro lado, teve como conseqüência a constituição do Estado em ator político privilegiado e autoritário. Assim é que os setores cafeeiros, num primeiro momento, conquistaram a intervenção do Estado a seu favor, mas, em seguida, tal intervenção implicou o aparelhamento crescente do Estado e o seu fortalecimento, levando a uma situação de desarmonia entre classe e Estado. Este, não tendo que ser o regulador de um ambiente político competitivo, constituiu-se em ator político de destaque (p. 210). Dessa forma, a Primeira República é um momento fundamental do processo de state-building brasileiro, não tendo esse, portanto, se esgotado nos anos inicias do Império, como pensam alguns autores.

O último capítulo desta parte - "Mercado, Estado e cidadania: as estratégias brasileiras de desenvolvimento" - tem como objetivo analisar "as relações entre política e desigualdade social no Brasil, levando em conta as oportunidades para o crescimento econômico e seus limites” (p. 213). Lançando mão mais uma vez da história comparada, Reis constata que diversos países que formam os chamados segundo e terceiro mundos se valeram de estratégias distintas de desenvolvimento e que tais estratégias tiveram consequiências diferentes sobre a democracia (p. 218). No caso específico do Brasil, Reis chama a atenção para o fato de que "a predominância do capitalismo de Estado implicou uma noção de cidadania fortemente vinculada ao Estado" (p. 219). Assim, a nossa cidadania é muito mais fruto de um despotismo esclarecido do que de uma sociedade civil vigorosa (p. 220). Dessa forma, acima dos interesses de grupos particulares, existia o projeto nacional, o desenvolvimentismo da era Vargas como um elemento de coesão da unidade nacional. Contudo, a crise dos anos 1980 e a redefinição do projeto econômico brasileiro puseram um fím não só no desenvolvimentismo como ideologia nacional, como também no seu mecanismo de sustentação, qual seja, o corporativismo como forma privilegiada de representação de interesses (p. 221-22). O problema, porém, é que nada parece ter sido colocado no seu lugar. O que presenciamos atualmente é uma expansão da desigualdade, das ineficiências das políticas públicas de caráter social, tudo isso acompanhado por um crescimento da apatia política e da indiferença da população mais pobre frente à democracia.

Essas últimas questões são discutidas de forma extremamente interessante nos dois capítulos da quarta parte do livro. O primeiro capítulo desta última parte - "Opressão burocrática: o ponto de vista do cidadão" - busca pensar a questão da opressão burocrática no Brasil tal qual vivenciada pelos cidadãos comuns. A fonte de informações escolhida pela autora constitui-se de um conjunto de correspondências enviadas ao então ministro extraordinário da desburocratização, Hélio Beltrão, que, no final da década de 1970, havia pedido à população que lhe informasse, por correspondência direta, sobre os problemas com a administração pública. O objetivo de Reis é tentar identificar nessas cartas qual a percepção que o brasileiro comum tem da burocracia e da autoridade pública. As cartas são, em ambos os casos, reveladoras. Elas tratam dos mais diversos assuntos (aposentadoria, fundos de pensão, hospitalização, assistência médica, impostos, aquisi-

7 Essa perspectiva tem tradição tanto na Sociologia Política internacional quanto nacional. Um dos expoentes dessa posição, como se sabe, é Reinhard Bendix, para quem "modernidade" e "tradição" não são, na realidade concreta, termos absolutamente antagônicos. Por exemplo, "Uma comparação do desenvolvimento no Japão e na Alemanha ressalta claramente a consideração de que as tradições podem facilitar, bem como dificultar, o rápido desenvolvimento. Mas até que ponto a 'tradição' fará isto ou aquilo, depende não só das características dadas de um país, mas também da maneira como esses 'dados' entram no 'gerenciamento político' do desenvolvimento". BENDIX, 1996, p. 239. Na Sociologia Política brasileira, o clássico trabalho de Victor Nunes Leal sobre o coronelismo já havia alertado para a relação "simbiótica" entre poder público e poder privado nesse fenômeno da política nacional: " $O$ fortalecimento do poder público, pois, acompanhado de correspondente enfraquecimento do 'coronelismo' tem, ao contrário, contribuído para consolidar o sistema [coronelista] garantindo aos condutores da máquina oficial do Estado quinhão mais substancioso na barganha que o configura". LEAL, 1978 , p. 255. 
ção de casa própria etc.). Contudo, todas as cartas revelam algo em comum: a burocracia é um mal absoluto, um monstro frio e ineficiente que menospreza as tragédias pessoais (p. 244-49). Frente a esse mal absoluto somente a "boa autoridade" pode solucionar os problemas pessoais negligenciados pela burocracia. Reis nota que a burocracia no Brasil, em grande parte pela sua incapacidade de resolver os problemas mais comezinhos $^{8}$, é, para o cidadão médio, puramente sinônimo de "formalismo estéril", mera "fonte de problemas e de infelicidade social". Não é à toa que nas cartas não aparece em nenhum momento a noção de "servidor público" (p. 253). Contra essa fonte de todos os males, os cidadãos vêem uma única salvação: "a interferência de uma autoridade carismática" (p. 255). Uma autoridade cuja função política é, essencialmente, transformar direitos em favores. A boa autoridade não é aquela que cumpre rigorosamente as regras, mas aquela que se contrapõe ao monstro burocrático para conceder benefícios (p. 256 e ss.). Dessa forma, podemos dizer que o problema da "opressão burocrática" no Brasil tem uma série de consequiências perversas: a transformação do regime do predomínio das regras em mera "desfuncionalidade" impede o advento e o predomínio da legitimidade burocrática, isto é, a total incapacidade da "burocracia" para atender as mínimas reivindicações da população reitera a crença de que tais reivindicações só podem ser atendidas pela via do favor vindo de cima, concedido pela "boa autoridade". Ora, o favor só é concedido a quem se conhece, a quem se faz cliente do Estado; por conseqüência, todos os que não são "amigos do Rei" devem ficar de fora da distribuição das benesses estatais. Como diz Reis, "o cidadão permanece como cliente do Estado" e a sociedade brasileira permanece imersa em um "visão de mundo que reforça a naturalidade da desigualdade e da missão ideal da autoridade para compensá-la" (p. 166-7). O discurso contra a desburocratização tem, assim, implicações claramente conservadoras: sanciona uma "visão do mundo em que os recursos da autoridade são a única alternativa para se reduzir a opressão burocrática, [...] contribui [portanto] para reforçar o mito de uma sociedade impotente, composta de cidadãos que nada têm a fazer senão buscar a patronagem do poder" (268).

No capítulo final - "Pobreza, desigualdade e identidade política" - Reis lança a hipótese de que "a pobreza extrema, em combinação com a desigualdade, gera uma espécie de identidade social restritiva, alienada da esfera política". Para a autora, o apartheid social brasileiro é uma variável fundamental na atrofia da esfera pública e nas dificuldades que os setores mais pobres têm para construir uma identidade política (p. 274). Tudo isso, como se percebe, com evidentes efeitos negativos sobre a democracia. Para a autora, os níveis extremados de pobreza e desigualdade no Brasil impedem o surgimento, entre os mais pobres, de um sentimento de pertencimento a uma comunidade política e, por conseguinte, um afastamento em relação as questões públicas ${ }^{9}$. Cidadania e democracia são, para esses setores, palavras e realidades desprovidas de significado. As elites brasileiras percebem o problema da pobreza e da desigualdade como o principal problema nacional. Contudo, mostra-nos Reis, elas não se vêem como parte do problema. Parecem esquecer que também participam do grupo que governa e conduz o país (p. 287). Em plena concordância com isso, está o fato de essa elite ter uma concepção puramente formal de democracia e entender que a ajuda à pobreza passa apenas por alguma forma de assistencialismo (p. 285). Para a autora, o fundamental hoje, no Brasil, não é a preservação da democracia, mas sim a qualidade da democracia de que desfrutamos (p. 293).

$$
* * *
$$

Para finalizar, vale recolocar a questão apresentada anteriormente: em que medida Elisa Pereira Reis responde as questões teóricas e metodológicas colocadas no início do seu livro e reproduzidas acima? A meu ver, a autora não produz uma resposta satisfatória àquelas indagações. Em grande parte acho que isso ocorre pela própria natureza do livro em questão. Este trabalho, como disse acima, é constituído por uma série de artigos que, embora tenham preocupações teóricas comuns, tratam delas de maneira bastante diferenciadas. É preciso lembrar que uma parte significativa do texto trata mais pesadamente de questões históricas, deixan-

\footnotetext{
8 O que nos levaria a dizer, quanto a esse ponto, que o grande problema no Brasil não é 0 excesso de burocracia, mas a falta dela, se entendermos esse termo no sentido weberiano.

9 Além da pobreza e da desigualdade, é preciso sempre lembrar o desrespeito com que os mais pobres e as minorias são tratadas pelas instituições policiais e de justiça no Brasil. A indiferença frente à democracia não se origina, ao meu ver, apenas de um desânimo frente às dificuldades da vida material, mas também (talvez principalmente) do fato de que para essa parte da população, acuada por uma polícia assassina e abandonada por um judiciário corrupto e ineficiente, a democracia efetivamente nada significa.
} 
do poucas páginas, geralmente as iniciais, para as discussões de natureza teórica. Os textos mais teóricos (aqueles da primeira parte), como disse anteriormente, são um tanto quanto frustrantes. Neles a autora apresenta as questões de teoria e método, mas não as aprofunda e as discute, sobretudo, a partir da ótica dos clássicos. Enfim, o fato é que o livro é uma coletânea de artigos que, embora partilhem a preocupação de conjugar teoria sociológica e história, não têm fôlego suficiente, pela sua própria condição de artigo, para tratar dessas questões com a profundidade que elas merecem. Diferente seria se o livro fosse planejado, do começo ao fim, com o intuito de cumprir tal objetivo. De qualquer forma, a presente publicação apresenta ao leitor questões teóricas fundamentais e coloca-nos em contato com análises penetrantes da realidade brasileira. Penso mesmo que os artigos que têm esse último ponto como objeto constituem-se na parte mais interessante do livro.

Recebido para publicação em agosto de 1999.

Renato Monseff Perissinotto (renatomp@ @oruja.humanas.ufpr.br) é Doutor em Ciências Sociais pela Universidade Estadual de Campinas (UNICAMP) e Professor de Ciência Política na Universidade Federal do Paraná (UFPR).

\section{REFERÊNCIASBIBLIOGRÁFICAS}

BENDIX, R. 1996. Construção nacional e cidadania. São Paulo : Edusp.

GUIDENS, A. 1982. Commentary on the Debate. Theory and Society, New York/Amsterdan, Vol. 11, nº 4, p. 527-539, July.

KISER, E. 1996. The Revival of Narrative in Historical Sociology: what Rational Choice Theory Can Contribute. Politics and Society, New York, Vol. 24, nº 3.

LEAL, V. N. 1978. Coronelismo, enxada e voto. São Paulo : Alfa-Ômega.

LUKES, S. 1980. O poder. Brasília : Ed. da UnB.

REIS, E. P. 1979. The Agrarian Roots of the Authoritarian Modernization in Brazil: 1880-1930. PhD. Dissertation. Massachusets, Massachusets Institute of Technology.

WEBER, M. 1984. Economia y sociedad. México : Fondo de Cultura Económico. 